\title{
Fertility rates and perinatal outcomes of adolescent pregnancies: a retrospective population-based study ${ }^{1}$
}

\author{
Maria de Lourdes de Souza² \\ Fiona Ann Lynn ${ }^{3}$ \\ Linda Johnston ${ }^{4}$ \\ Eduardo Cardoso Teixeira Tavares ${ }^{5}$ \\ Odaléa Maria Brüggemann ${ }^{6}$ \\ Lúcio José Botelho7
}

\begin{abstract}
Objective: analyze trends in fertility rates and associations with perinatal outcomes for adolescents in Santa Catarina, Brazil. Methods: a population-based study covering 2006 to 2013 was carried out to evaluate associations between perinatal outcomes and age groups, using odds ratios, and Chi-squared tests. Results: differences in the fertility rate among female adolescents across regions and time period were observed, ranging from 40.9 to 72.0 per 1,000 in mothers aged 15-19 years. Adolescents had fewer prenatal care appointments than mothers $\geq 20$ years, and a higher proportion had no partner. Mothers aged 15-19 years were more likely to experience preterm birth (OR:1.1; CI:1.08-1.13; p<0.001), have an infant with low birthweight (OR:1.1; $\mathrm{CI}: 1.10-1.15 ; \mathrm{p}<0.001)$ and low Apgar score at 5 minutes (OR:1.4; CI:1.34-1.45; p<0.001) than mothers $\geq 20$ years, with the odds for adverse outcomes greater for those aged 10-14 years. Conclusion: this study provides evidence of fertility rates among adolescents remaining higher in regions of social and economic deprivation. Adolescent mothers and their infants more likely to experience adverse perinatal outcomes. Nurses, public health practitioners, health and social care professionals and educators need to work collaboratively to better target strategies for adolescents at greater risk; to help reduce fertility rates and improve outcomes.
\end{abstract}

Descriptors: Adolescent; Pregnancy in Adolescence; Fertility; Prenatal Care; Maternal Health; Public Health.

\footnotetext{
1 Supported by Fundação de Amparo a Pesquisa e Inovação do Estado de Santa Catarina (FAPESC), Brazil, process \#1436/2012, Termo de Outorga 13075/2012 -PPSUS 03/2012.

2 PhD, Professor, Universidade Federal de Santa Catarina, Florianópolis, SC, Brazil.

${ }^{3}$ PhD, Professor, School of Nursing \& Midwifery, Queen's University, Belfast, Northern Ireland, United Kingdom.

${ }^{4}$ PhD, Professor, Lawrence S. Bloomberg Faculty of Nursing, University of Toronto, Toronto, CA, Canada.

${ }^{5}$ Physician, Hospital Baía Sul, Florianópolis, SC, Brazil.

${ }^{6} \mathrm{PhD}$, Associate Professor, Universidade Federal de Santa Catarina, Florianópolis, SC, Brazil.

7 Doctoral student, Universidade Federal de Santa Catarina, Florianópolis, SC, Brazil. Associate Professor, Universidade Federal de Santa Catarina, Florianópolis, SC, Brazil.
}

\section{How to cite this article}

Souza ML, Lynn FA, Johnston L, Tavares ECT, Brüggemann OM, Botelho LJ. Fertility rates and perinatal outcomes of adolescent pregnancies: a retrospective population-based study. Rev. Latino-Am. Enfermagem. 2017;25:e2876.

[Access month day year ]; Available in: DOI: http://dx.doi.org/10.1590/1518-8345.1820.2876. 


\section{Introduction}

National fertility rates among adolescents are commonly used as an indicator for children and young people's health. While there has been a decline in the birth rate globally in recent years, pregnancy in adolescence remains a public health concern. The global birth rate, or age-specific fertility rate, for mothers aged 15 to 19 from 2007 to 2012 has been reported as 50 per 1,000 . At national levels, higher rates are consistently reported for developing nations in sub-Saharan Africa; however, rates for Brazil are consistently higher than the global rates, with a rate of 68 in 1,000 reported in 2012, which is among the highest rates reported in Latin America and the Caribbean ${ }^{(1)}$. The World Health Organization (WHO) also reports that half of all births to adolescent mothers occur in just seven countries, Brazil being one of these $\mathrm{e}^{(2)}$.

Adolescent pregnancy has been recognized as a major contributing factor to maternal and child mortality, morbidity and poverty ${ }^{(3)}$. Epidemiological studies indicate that adolescent pregnancies lead to a greater proportion of infants being born preterm and/or with low birth weight, which in turn have been associated with higher mortality rates ${ }^{(4-7)}$. Low socioeconomic conditions, risky lifestyle behaviors, poor adherence to prenatal care and biological immaturity have also been suggested as possible explanations for adverse obstetric and perinatal outcomes in this group ${ }^{(4-5,8)}$.

With the Millennium Development Goals 4 (reducing child mortality) and 5 (improving maternal health), public health strategies for tackling teenage pregnancy rates have been promoted in both developed and developing nations ${ }^{(9-10)}$. However, regional differences may persist and better targeting vulnerable populations may result in greater improvements. Consequently, evaluating the trends in fertility rates at a national and regional level is vital to comprehend any progress made and to indicate targets for the future.

The aim of this study is to understand the characteristics and health-related outcomes of live births to teenage mothers in comparison to adult mothers by analysing trends in age-specific fertility rates and associations with selected perinatal outcomes across one State in Brazil from 2006 to 2013 inclusive. The State of Santa Catarina has a population of approximately 6.7 million inhabitants. Regional figures state that $15.7 \%$ ( $n=1.04$ million) of the population was aged 1019 years in 2013, which is comparable to the national figure of $17.1 \%$ ( $n=34.29$ million). The State of Santa
Catarina consists of nine regions that differ in terms of social and economic development, with inherent health disparities and inequalities*. Public health policy makers at a regional level in Santa Catarina experience issues similar to other developing regions. As such, monitoring and understanding trends is an important step towards assessing the need for action, particularly in areas with limited resources.

\section{Methods}

A population-based study covering the period from 2006 to 2013 was carried out. The research population included all live births across the State of Santa Catarina. Data were extracted from the Information System of Live Births (SINASC) database of the Ministry of Health, Brazil, through the DATASUS website, and from the State Health Department of Santa Catarina.

Age-specific fertility rates were calculated as a ratio, defined by the United Nations (UN) ${ }^{*}$ as the annual number of births to women of a specified age or age group per 1,000 women in that age group. Data for the State of Santa Catarina were collected for the years 2006-2013 inclusive. However, data by region were unavailable for the year 2013, due to the absence of regional data for the denominator. Hence, age-specific fertility rates at the regional level were calculated for the years 2006-2012.

Data on maternal characteristics included age (grouped as $10-14$ years, $15-19$ years, or $\geq 20$ years of age), years of formal education (grouped as $<8$ or $\geq 8$ years) and marital status, which was categorized as with partner (married or co-habiting) or without partner (single, widowed, separated or divorced). Pregnancyrelated variables included the number of prenatal appointments attended ( $<7$ or $\geq 7$ appointments) and type of delivery (vaginal birth or caesarean section). Infant outcomes included gestational age at birth $(<37$ or $\geq 37$ weeks), birth weight ( $<2500$ grams or $\geq 2500$ grams) and Apgar at 5 minutes, categorized as scores $\leq 7$ or 8 to 10 . The Apgar score establishes the clinical condition of all newborn infants immediately after delivery, regardless of the delivery mode, with a high score indicating good physical condition(8). Aggregate data were collected on all live births by health region for 2006-2013. The nine regions in the State of Santa Catarina, as defined by the Health Department, are Serra Catarinense (Mountain Range), Extremo Oeste (Great West), Meio Oeste (Midwest), Foz do Rio Itajaí (Itajaí River Mouth), Vale do Itajaí (Itajaí Valley), Grande Florianópolis (Greater Florianópolis), Sul

*United Nations Children's Fund and World Health Organization (UNICEF). Low Birthweight: Country, regional and global estimates [Internet]. New York: UNICEF; 2004 [Retrieved on Dec 14 2015]. Available at: http://www.unicef.org/publications/files/low_birthweight_from_EY.pdf 
(South), Nordeste (Northeast) and Planalto Norte (Northern Plateau). The UN Human Development Index (HDI) is a measure of the standard of living and takes into account education, life expectancy and population income. According to published HDI scores*, based on 2010 data, the regions of Santa Catarina with average lower HDI scores than the State score of 0.774 were Extremo Oeste, Meio Oeste, Planalto Norte and Serra Catarinense. The regions with higher HDI scores than the State included Vale do Itajaí, Grande Florianópolis and Nordeste.

\section{Data analysis}

Population statistics relating to age-specific fertility rates among adolescents are most frequently reported for those aged 15 to 19 years. As such, data were analyzed by age groups 10 to 14 years and 15 to 19 years. Age-specific fertility rates for female adolescents in the State of Santa Catarina were calculated for each year (2006-2013) to identify trends within this population. Odds Ratios (OR) and 95\% Confidence Intervals (CI) were calculated to measure the level of association between specified age groups and perinatal outcomes. Chi-squared tests for statistical significance were also performed. Data were analyzed using electronic support.

This study was developed in the context of Project TO 13075/2012 - FAPESC, Opinion No. 120.343, No. 169.110 in 2012. Ethical guidelines for research development were complied with in accordance with Resolution No. $466 / 2012$ of the Brazilian Federal Health Department. This research did not involve direct recruitment and consent of human subjects, as secondary analysis was conducted on data collected from publicly available sources that contain anonymized data.

\section{Results}

In Santa Catarina State, during the period 2006 to 2013 , there were 115,559 live births to mothers aged 10 to 19 years, representing a proportion of nearly $17 \%$ of all live births $(n=685,525) .3 .8 \%(n=4,397)$ of births to adolescent mothers were in the youngest cohort aged 10 to 14 years. Across the State of Santa Catarina, the fertility rate to mothers aged 10-14 years ranged from 1.9 to 2.3 per 1,000 between 2006-2013 and from 49.1 to 55.0 per 1,000 female adolescents aged $15-19$ years. In Figure 1, the trend in the fertility rate among female adolescents is illustrated in the state of Santa Catarina from 2006-2013 and by region, with data available for the period 2006-2012, indicating an overall steady decline. Birth rates to mothers' aged 10-19 remain highest in the regions, with an average lower standard of living (Serra Catarinense, Planalto Norte, Meio Oeste and Extremo Oeste). The regions with lower rates were the Nordeste, Vale do Itajaí and Grande Florianópolis, which represent largely urban areas that are more economically and socially developed, with higher average standards of living, as quantified by HDI scores**.
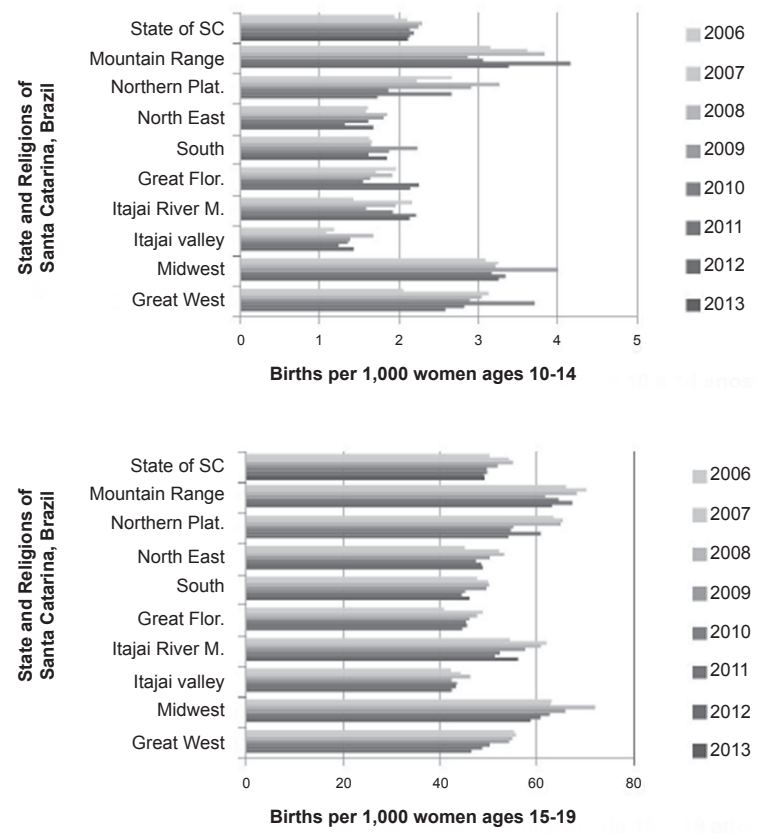

Figure 1 - Trends in fertility rates among adolescents by State and region of Santa Catarina (SC), Brazil.

In Table 1, the years of formal education and marital status of the mothers are reported by age group for 2006 to 2013. With respect to education, $75 \%(n=3,277)$ of the adolescents aged $10-14$ years had less than eight years of formal schooling; this proportion dropped to $38 \%(n=41,876)$ for those aged 15-19 years, as expected a priori. In the group of women aged $\geq 20$ years, $72 \%(n=407,615)$ had eight or more years of education, with almost a third (28\%; $\mathrm{n}=158,889)$ reporting less than eight years. As expected a priori, differences between groups in years of formal education and marital status were statistically significant $(p<0.001)$. With regard to marital status, the groups 10-14 years and $15-19$ years had a higher proportion of mothers living without a partner, $80.6 \%(n=3,545)$ and

\footnotetext{
*Programa das Nações Unidas para o Desenvolvimento, Brasil (PNUD). Atlas do Desenvolvimento Humano. Santa Catarina (Estado) [Internet]. Brasília; 2015 [Retrieved on $14 \mathrm{dez}$ 2015]. Available at: http://www.atlasbrasil.org.br/2013/pt/perfil_uf/santa-catarina.

**Programa das Nações Unidas para o Desenvolvimento, Brasil (PNUD). Atlas do Desenvolvimento Humano. Santa Catarina (Estado) [Internet]. Brasília; 2015 [Retrieved on Dec 14 2015]. Available at: http://www.atlasbrasil.org.br/2013/pt/perfil_uf/santa-catarina.
} 
$66.6 \%(n=73,992)$, respectively. For women aged $\geq 20$ years, this figure was $40.4 \%(n=230,534)$.

In Table 2, the pregnancy-related outcomes of prenatal appointments and type of delivery are reported, as well as infant outcomes of gestational age at birth, birth weight and Apgar score at five minutes for the three maternal age groups. Adolescent mothers were more likely to experience inadequate prenatal care, as defined by less than seven prenatal appointments, when compared to mothers aged $\geq 20$ years, with the odds being greater for adolescents aged 10-14 years (OR: 2.40; 95\% CI: 2.26-2.54; p value: <0.001) and those aged $15-19$ years (OR: $1.72 ; 95 \%$ CI: $1.70-1.75$; $\mathrm{p}$ value: $<0.001)$. In relation to the type of delivery, the percentage of caesarean sections among those aged 10-14 years and 15-19 years was similar, with $43.2 \%(n=1,901)$ and $42.1 \%(n=46,751)$, respectively. This compares to a higher percentage among mothers aged $\geq 20$ years $(59.7 \% ; n=340,537)$, with adolescent mothers statistically significantly less likely to have a caesarean section $(p<0.001)$ than the older cohort, with statistical significance.

The number of preterm births $(<37$ weeks' gestation) was higher in the 10-14 years age group $(13.6 \% ; n=598)$, when compared to the other two maternal age groups: $15-19$ years old $(9.2 \% ; n=10,266)$ and $\geq 20$ years $(8.5 \% ; n=48,198)$. An odds ratio (OR) of 1.71 (95\% CI: 1.57-1.86; p value: <0.001) confirms that those aged 10-14 years had a significantly higher chance of a preterm birth compared to women $\geq 20$ years of age. This association continued for those aged 15-19 years (OR: 1.1 ; 95\% CI: 1.08-1.13; p value: <0.001). With regard to the delivery of a low birth weight infant, pregnant women aged 10-14 years were more likely to have an infant weighing $<2500 \mathrm{~g}$ at birth (OR: 1.53 ; 95\% CI: $1.40-1.68$; $p$ value: <0.001) compared to women $\geq 20$ years. Although the odds were reduced for women aged 15-19 years, they remained statistically significant (OR: 1.13; 95\% CI: 1.10-1.15; p value: $<0.001$ ). In relation to the Apgar score at 5 minutes, which is an indicator of the infant's physical condition; mothers aged $10-14$ years were 1.82 times more likely to have an infant with an Apgar score of 7 or less (95\% CI: 1.56-2.13; p value: <0.001); while mothers aged 15-19 years were 1.39 times more likely (95\% CI: $1.34-$ 1.45 ; $p$ value: $<0.001)$ when compared to infants born to mothers aged $\geq 20$ years. When infant Apgar scores at 5 minutes were compared between adolescents aged 10-14 years and those aged $15-19$ years, no statistically significant differences were observed $(p=0.07)$.

Table 1 - Level of education and marital status of the pregnant women by maternal age in Santa Catarina, Brazil, 2006-2013

\begin{tabular}{|c|c|c|c|c|}
\hline \multirow{2}{*}{ Maternal characteristics } & $10-14$ years & $15-19$ years & $20+$ years & \multirow{2}{*}{ P value } \\
\hline & $n^{\dagger}(\%)$ & $\mathrm{n}^{\dagger}(\%)$ & $\mathrm{n}^{\dagger}(\%)$ & \\
\hline \multicolumn{5}{|l|}{ Education (years) } \\
\hline Less than 8 years & $3,277(74.5)$ & $41,876(37.7)$ & $158,889(27.9)$ & \multirow[t]{3}{*}{$<0.001$} \\
\hline 8 or more & $1,089(24.8)$ & $68,614(61.7)$ & $407,615(71.5)$ & \\
\hline Missing & $31(0.7)$ & $672(0.6)$ & $3,462(0.6)$ & \\
\hline \multicolumn{5}{|l|}{ Marital status } \\
\hline Without partner & $3,545(80.6)$ & $73,992(66.6)$ & $230,534(40.4)$ & \multirow[t]{3}{*}{$<0.001$} \\
\hline With partner & $803(18.3)$ & $35,949(32.3)$ & $334,867(58.8)$ & \\
\hline Missing & $49(1.1)$ & $1,221(1.1)$ & $4,565(0.8)$ & \\
\hline
\end{tabular}

$* P$ value - Chi squared test for statistically significant differences between groups

$+n$ - number of pregnant women

Table 2 - Prenatal and perinatal outcomes for live births by maternal age group in Santa Catarina, Brazil, 20062013

\begin{tabular}{|c|c|c|c|c|c|}
\hline \multirow{2}{*}{ Perinatal outcomes } & \multicolumn{2}{|c|}{$10-14$ years } & \multicolumn{2}{|c|}{$15-19$ years } & \multirow{2}{*}{$\frac{20+\text { years }}{n^{*}(\%)}$} \\
\hline & $n^{*}(\%)$ & $\mathrm{OR}^{\dagger}\left(95 \% \mathrm{Cl}^{\S}\right)$ & $n^{*}(\%)$ & $\mathrm{OR}^{\dagger}\left(95 \% \mathrm{Cl}^{\S}\right)$ & \\
\hline \multicolumn{6}{|c|}{ Prenatal care appointments } \\
\hline$<7$ & $2,177(49.5)$ & $2.40^{\ddagger}$ & $46,000(41.4)$ & $1.72 \ddagger$ & $165,892(29.1)$ \\
\hline$\geq 7$ & $2,194(49.9)$ & $(2.26-2.54)$ & $64,497(58.0)$ & $(1.70-1.75)$ & $400,640(70.3)$ \\
\hline Missing & $26(0.6)$ & & $665(0.6)$ & & $3,434(0.6)$ \\
\hline \multicolumn{6}{|l|}{ Type of delivery } \\
\hline Caesarean section & $1,901(43.2)$ & $0.51^{\ddagger}$ & $46,751(42.1)$ & $0.49^{\ddagger}$ & $340,537(59.7)$ \\
\hline Vaginal birth & $2,492(56.7)$ & $(0.48-0.55)$ & $64,336(57.9)$ & $(0.48-0.50)$ & $229,098(40.2)$ \\
\hline Missing & $4(0.1)$ & & $75(<0.1)$ & & $331(0.1)$ \\
\hline
\end{tabular}


Table 2 - (continuation)

\begin{tabular}{|c|c|c|c|c|c|}
\hline \multirow{2}{*}{ Perinatal outcomes } & \multicolumn{2}{|c|}{$10-14$ years } & \multicolumn{2}{|c|}{$15-19$ years } & \multirow{2}{*}{$\frac{20+\text { years }}{n^{*}(\%)}$} \\
\hline & $\mathrm{n}^{*}(\%)$ & $\mathrm{OR}^{\dagger}\left(95 \% \mathrm{Cl}^{\S}\right)$ & $n^{*}(\%)$ & $\mathrm{OR}^{\dagger}\left(95 \% \mathrm{Cl}^{\S}\right)$ & \\
\hline \multicolumn{6}{|l|}{ Length of gestation } \\
\hline$<37$ weeks & $598(13.6)$ & $1.71^{\ddagger}$ & $10,266(9.2)$ & $1.10^{\ddagger}$ & $48,198(8.5)$ \\
\hline$\geq 37$ weeks & $3,776(85.9)$ & $(1.57-1.86)$ & $100,341(90.3)$ & $(1.08-1.13)$ & $519,477(91.1)$ \\
\hline Missing & $23(0.5)$ & & $555(0.5)$ & & $2,291(0.4)$ \\
\hline \multicolumn{6}{|l|}{ Birth weight } \\
\hline$<2500$ grams & $504(11.5)$ & $1.53^{\ddagger}$ & $9,666(8.7)$ & $1.13^{\ddagger}(1.10-1.15)$ & $44,436(7.8)$ \\
\hline$\geq 2500$ grams & $3,893(88.5)$ & $(1.40-1.68)$ & $101,486(91.3)$ & & $525,479(92.2)$ \\
\hline Missing & - & & $10(<0.1)$ & & $51(<0.1)$ \\
\hline \multicolumn{6}{|l|}{ Apgar at $5 \mathrm{~min}$} \\
\hline$\leq 7$ & $167(3.8)$ & $1.82^{\ddagger}$ & $3,264(2.9)$ & $1.39^{\ddagger}$ & $12,129(2.1)$ \\
\hline 8 to 10 & $4,211(95.8)$ & $(1.56-2.13)$ & $107,692(96.9)$ & $(1.34-1.45)$ & $556,731(97.7)$ \\
\hline Missing & $19(0.4)$ & & $206(0.2)$ & & $1,106(0.2)$ \\
\hline
\end{tabular}

$* \mathrm{n}$ - number of pregnant women

+ OR - Odds ratio with age group of 20 years or more as reference

$\neq p<0.001$ ( $P$ value - Chi-squared test for statistically significant differences between groups)

$\S \mathrm{CI}$ - Confidence Intervals

\section{Discussion}

The decline in the fertility rate among adolescents in the State of Santa Catarina is in line with the overall rate in Brazil, other developing nations and with the global trend reported by the WHO. In a comparative study of 29 countries in Africa, Asia, Latin America and the Middle East between 2010 and 2011, the average proportion of pregnancies to adolescents was $25.9 \%{ }^{(11)}$. While Brazil and the State of Santa Catarina are below this average; they remain above average when compared to more developed countries ${ }^{(12)}$. With respect to fertility rate trends among adolescents across regions in the State of Santa Catarina, differences were observed. Regions with a lower standard of living continue to report higher fertility rates to adolescent mothers. These regions are typically characterized as experiencing more economic deprivation, with greater health, social and educational disparities. Adolescence is a stage of development that is greatly influenced by local cultural, social and economic conditions, alongside biological changes, psychological effects, lifestyle behaviors and social and cultural values ${ }^{(6)}$. The high number of adolescent pregnancies has previously been attributed to a failure of public health policies in the prevention of unplanned pregnancies and in sexual and reproductive health education reaching young people ${ }^{(13)}$. Many adolescents are deterred from engaging in the preference, prevention and promotion approach primary health care systems approach. As such, greater effort is needed in targeting appropriate strategies and effective interventions to adolescents in regions that are falling behind the State and/or Brazilian average ${ }^{(14)}$.
Complications in teenage pregnancies have previously been associated with adverse social conditions, low levels of education, marital status, lack of family support and, above all, inadequate prenatal care ${ }^{(13)}$. The findings from this paper support this evidence. Effective prenatal care is able to detect infectious diseases that have the potential for vertical transmission and a range of adverse conditions that may impair the health of the mother and fetus, such as malaria, HIV, rubella, syphilis and hepatitis. Above all, it is a simple task during a prenatal visit to check maternal and fetal vital signs, estimate gestational risks and assist in preventing adverse outcomes ${ }^{(15)}$. Prenatal care is a valuable tool for monitoring the health of the mother, as well as monitoring the on-going development of the fetus, and has been associated with lower rates of preterm birth and a reduction in infants of low birth weight $^{(13)}$. Prenatal care for all adolescents therefore needs to commence early in gestation to ensure that early identification of risk takes place and that any follow-up actions required are taken ${ }^{(16)}$.

In this population-based study, the incidence of preterm birth (<37 gestation weeks) was higher among mothers aged 10 to 14 year olds than those aged 15 to 19 years and 20 years old or more, which is similar to figures reported in developing countries ${ }^{(12)}$. It should also be noted that the incidence of maternal near miss in childbirth and postpartum hospital in Brazil among adolescents aged 10-14 years has previously been reported as 15.7 per 1,000 live births and 9.8 per 1,000 live births for those aged 15-19 years; in the 20-34 years age group, this figure equals 9.4 per 1,000 live births ${ }^{(17)}$. considering all teenagers as a single homogenous cohort creates a barrier for consensus on 
the issue of preventing maternal near miss ${ }^{(4-5,18)}$. The smaller cohort of mothers aged 10-14 years require personalized care in the intrapartum and postpartum period if improvements are to be observed.

The data obtained on the birth weight of live births that occurred in Santa Catarina confirm previous findings in the literature on the relationship between maternal age and birth weight of infants, particularly highlighting the association between adolescent pregnancy and low infant birth weight. Previous studies have reported an average prevalence of low infant birth weight corresponding to $12 \%$ for all adolescent groups assessed ( $<16$ years, $16-17$ years and $18-19$ years old) $(13,19)$, placing the State of Santa Catarina in a slightly better context than most low- and middle-income countries. Nevertheless, the birth weight of infants in developed and developing countries remains a major factor affecting neonatal morbidity and mortality, and is an important indicator of public health ${ }^{(6,8)}$. Likewise, nutrition and lifestyle habits post-conception (use of alcohol, tobacco, drug misuse, exposure to infections, such as malaria and HIV) also influence fetal growth and development, as well as the duration of pregnancy ${ }^{(16)}$. Women with unfavorable socioeconomic conditions often have infants with low birth weight, which in turn has been linked to poor nutrition and unhealthy lifestyle habits ${ }^{(5,16)}$.

Low birth weight may result in a risk to the survival and development of the infant. In addition, children with teenage mothers are in greater need of a social support network, which is not always available. Thus, the growth and development of these children, with follow-up health checks through attendance at well-baby clinics, is paramount. This requires nurses to take care of the adolescent mother/child dyad. The health care network has to be prepared to offer adequate support to those clients of greater vulnerability, both during attendance at the health services and at home. Adolescents are women in the process of discovering their sexuality and are not always prepared for motherhood(10,13-14,16).

With regard to delivery, the preferred mode is vaginal, as long as there are no medical indications for a caesarean section, which may include two or more previous caesareans, fetal macrosomia or shoulder dystocia(20). This study found that the prevalence of caesarean sections in pregnant women younger than 20 years old was lower than those aged 20 years or more (42\% vs. $60 \%$ ), with significantly lower odds. Prenatal care may be a mediating factor in this, with adolescents receiving fewer prenatal care appointments and, therefore, less exposure to the introduction of planned obstetric intervention prior to labor and delivery. Similar findings have been reported across Brazil, while lower figures of less than $30 \%$ have been reported among other low- and middle-income countries ${ }^{(11)}$. The figures for the prevalence of caesarean sections reported within this study, across all age groups, exceed recommendations from the WHO to limit caesarean sections to between $10-15 \%$ of all births ${ }^{(21)}$. New regulations are being enforced in 2015 in Brazil(22), in an attempt to reduce the universally high rate of caesarean sections, by ensuring that pregnant women are informed of the risks, with the ultimate aim of reducing rates and creating a shift in the culture to informed choice and decision making by mothers.

In the early assessment of infant health, the Apgar score is an important tool to monitor the physical condition of newborns. According to the findings in this study, an Apgar score $<7$ occurred in $3 \%$ of births to adolescent mothers, which is similar to national data. A cohort study recently conducted in Brazil reported significant associations between neonatal mortality and birth weight, gestational age at birth, a low Apgar score at 5 minutes, the use of mechanical ventilation and congenital malformations(23). However, the use of the Apgar score in preterm infants has been reported to be inconsistent and any assumptions with respect to the predictive value of the Apgar score for infant mortality should also take into account a range of other factors, including social and economic conditions(24). Nevertheless, previous research aimed at assessing causal links between a range of maternal and pregnancyrelated variables and infant Apgar scores reported associations between the frequency of prenatal care and an Apgar score of less than seven ${ }^{(13)}$. The authors provided evidence that appropriate prenatal care halves the risk of an unsatisfactory Apgar score ${ }^{(13)}$. With adolescent mothers in this population-based study being more likely to experience inadequate prenatal care, preterm birth, having an infant of low birth weight and a low Apgar score, it is essential that health services be more easily accessible and supportive of this vulnerable group. One such initiative is the CERCA study, currently conducted across three Latin American cities, which aims to develop, implement and evaluate a communityembedded reproductive health care program for adolescents. This innovative study has the potential to improve outcomes for adolescents through a targeted sexual and reproductive health program ${ }^{(25)}$.

Reproductive health care requires acknowledgement of the complexities involved in adolescent pregnancy. It needs to take into consideration the social and cultural factors that may contribute to its occurrence. The adolescents may view pregnancy as an opportunity to acquire the desired family autonomy. Aside from this, the adolescent may not recognize the pregnancy nor 
many of the associated risks or social losses they may experience in becoming a mother(18,26).

In terms of study limitations, it should be noted that in calculating the fertility rates among adolescents aged 10-14 years, the denominator data related to all female adolescents aged 10-14 years in the State and each respective region. Consequently, the rates observed are likely to be an underestimation of the true fertility rate in this cohort. It would be more appropriate to employ an estimate of exposure to childbearing by females aged 10-14 years as the denominator. However, these data were unavailable. The reader should also reflect on the issue of reporting fertility rates among adolescents, instead of the rate of teenage pregnancy. This figure would undoubtedly be higher, as it would include not only all pregnancies that resulted in a live birth, but also those that resulted in a spontaneous miscarriage, termination of pregnancy or stillbirth. Understanding any disparities across regions in relation to the differences between pregnancy rates and fertility rates is difficult without the routine collection and dissemination of these data. Nevertheless, fertility rates are useful as a proxy measure at a local level to obtain a better understanding of trends, in order to target effective interventions and evaluate their efficacy.

\section{Conclusions}

The findings from this current study raise awareness for the continued observation and on-going analysis of fertility rates among adolescent mothers. There is a clear need for greater attention to adolescent mothers in health care services, in order to assist them and their infants, particularly in regions identified as having higher rates of teenage pregnancy. Adapting current public health strategies to target adolescents living in regions with a lower standard of living may ensure that the disparities observed are minimized, with the provision of effective interventions targeting this vulnerable group. In addition, a network of specialized support and care to pregnant adolescents, which incorporates reproductive, prenatal, psychological and social support and care, may contribute to the reduction of obstetric and fetal risks.

\section{References}

1. United Nations, Department of Economic and Social Affairs, Population Division. World Population Prospects: the 2015 revision [Internet]. Ney York: UN; 2015 [Access Dec 14 2015]. Available from: https://esa. un.org/unpd/wpp/

2. World Health Organization (WHO). Maternal, newborn, child and adolescent health: adolescent pregnancy
[Internet]. Geneva: WHO; 2015 [Access Dec 14 2015]. Available from: http://www.who.int/maternal_child_ adolescent/topics/maternal/adolescent_pregnancy/en/ 3. Azevedo WF, Diniz MB, Fonseca ES, Azevedo LM, Evangelista CB. Complications in adolescent pregnancy: systematic review of the literature. Einstein. [Internet]. 2015 Oct-Dec [Access Dec 14 2015];13(4):61826. Available from: http://www.scielo.br/pdf/eins/ v13n4/1679-4508-eins-S1679-45082015RW3127.pdf. doi: 10.1590/S1679-45082015RW3127

4. Leppälahti S, Gissler M, Mentula M, Heikinheimo O. Is teenage pregnancy an obstetric risk in a welfare society? A population-based study in Finland, from 2006 to 2011. BM] Open. [Internet]. 2013 Aug [Access Dec 14 2015];3(8):e003225. Available from: http:// bmjopen.bmj.com/content/3/8/e003225.full.pdf+html. doi:10.1136/bmjopen-2013-003225

5. Kramer KL, Lancaster JB. Teen motherhood in crosscultural perspective. Ann Hum Biol. [Internet]. 2010 Sep-Oct [Access Dec 14 2015];37(5):613-28. Available from: http://adc.bmj.com/content/94/3/239.long. doi: 10.3109/03014460903563434

6. Paranjothy S, Broughton H, Adappa R, Fone D. Teenage pregnancy: who suffers? Arch Dis Child. [Internet]. 2009 Mar [Access Dec 14 2015];94(3):239-45. Available from: http://adc.bmj.com/content/94/3/239.long . doi: 10.1136/adc.2007.115915

7. Klerman LV. Risk of poor pregnancy outcomes: is it higher among multiparous teenage mothers? J Adolesc Health. [Internet]. 2006 Jun [Access Dec 14 2015];38(6):761-4. Review. Available from: http://www.sciencedirect.com/ science/article/pii/S1054139X05002880. doi: 10.1016/j. jadohealth.2005.05.020

8. Penman-Aguilar A, Carter M, Snead MC, Kourtis AP. Socioeconomic disadvantage as a social determinant of teen childbearing in the U.S. Public Health Rep. [Internet]. 2013 Mar-Apr [Access Dec 14 2015];128 Suppl 1:5-22. Available from: https://www.ncbi.nlm.nih. gov/pmc/articles/PMC3562742/pdf/phr128s10005.pdf

9. United Nations. Millennium Development Goals. Achieving the Millennium Development Goals with Equality in Latin America and the Caribbean: progress and challenges [Internet]. Santiago, Chile: United Nations; 2010 [Access Dec 14 2015]. Available from: http://www.cepal.org/publicaciones/xml/5/39995/ Icg2460_MDG_ingles.pdf

10. Pan American Health Organization (PAHO). A Draft Concept Note. In: International Interagency Meeting: Current Evidence, Lessons Learned and Best Practices in Adolescent Pregnancy Prevention in Latin America and the Caribbean [Internet]. 2014 Mar 17-19; Managua, Nicaragua; 2014 [Access Dec 14 2015]. Available from: 
http://www.paho.org/derechoalaSSR/wp-content/ uploads/Documentos/Nicaragua-2014-Concept-Note.pdf 11. Ganchimeg T, Ota E, Morisaki N, Laopaiboon M, Lumbiganon $\mathrm{P}$, Zhang J, et al. Pregnancy and childbirth outcomes among adolescent mothers: a World Health Organization multicountry study. BJOG. [Internet]. 2014 Mar [Access Dec 14 2015];121 Suppl 1:40-8. Available from: http://onlinelibrary. wiley.com/doi/10.1111/14710528.12630/full

12. Santhya KG. Early marriage and sexual and reproductive health vulnerabilities of young women: a synthesis of recent evidence from developing countries. Curr Opin Obstet Gynecol. [Internet]. 2011 Oct [Access Dec 14 2015];23(5):334-9. Available from: http:// journals.Iww.com/co-obgyn/pages/articleviewer.aspx? year $=2011 \&$ issue $=10000 \&$ article $=00006 \&$ type $=$ abstra ct. doi: 10.1097/GCO.0b013e32834a93d2.

13. Baraldi ACP, Daud ZP, Almeida AM, Gomes FA, Nakano AMS. Adolescent pregnancy: a comparative study between mothers who use public and private health systems. Rev. Latino-Am. Enfermagem. [Internet]. 2007 Oct [Access Dec 14 2015];15(n.spe):799-805. Available from: http://www.scielo.br/pdf/rlae/v15nspe/13.pdf. doi: 10.1590/S0104-11692007000700014.

14. Maravilla JC, Betts KS, Abajobir AA, Couto e Cruz C, Alati R. The Role of Community Health Workers in Preventing Adolescent RepeatPregnancies and Births. JAdolescHealth. [Internet]. 2016 Oct [Access Nov 11 2016];59(4):37890. Available from: http://www.sciencedirect.com/ science/article/pii/S1054139X16300830. doi: 10.1016/j. jadohealth.2016.05.011.

15. Finlayson K, Downe S. Why do women not use antenatal services in low- and middle-income countries? A meta-synthesis of qualitative studies. PLoS Med. [Internet]. 2013 [Access Dec 14 2015];10(1):e1001373. Available from: http://www.ncbi.nlm.nih.gov/pmc/ articles/PMC3551970/pdf/pmed.1001373.pdf. doi: 10.1371/journal.pmed.1001373

16. Leal MD, Esteves-Pereira AP, Nakamura-Pereira M, Torres JA, Theme-Filha M, Domingues RM, et al. Prevalence and risk factors related to preterm birth in Brazil. Reprod Health. 2016 Oct 17 [Access Nov 11 2016];13(Suppl 3):127. Available from: https:// www.ncbi.nlm.nih.gov/pmc/articles/PMC5073982. doi: 10.1186/s12978-016-0230-0

17. Dias MAB, Domingues RMSM, Schilithz AOC, Nakamura-Pereira M, Diniz CSG, Brum IR, et al. Incidence of maternal near miss in hospital childbirth and postpartum: data from the Birth in Brazil study. Cad Saúde Pública. [Internet]. 2014 Aug [Access Dec 14 2015];30(Suppl 1):S1-S12. Available from: http:// www.scielo.br/pdf/csp/v30s1/en_0102-311X-csp30-s1-0169.pdf. doi: 10.1590/0102-311X00154213
18. Gibbs CM, Wendt A, Peters S, Hogue CJ. The impact of early age at first childbirth on maternal and infant health. Paediatr Perinat Epidemiol. [Internet]. 2012 Jul [Access Dec 14 2015];26(Suppl. 1):259-84. Available from: http://onlinelibrary.wiley.com/doi/10.1111/j.13653016.2012.01290.x/full

19. Vogel JP, Souza JP, Mori R, Morisaki N, Lumbiganon $\mathrm{P}$, Laopaiboon $\mathrm{M}$, et al. Maternal complications and perinatal mortality: findings of the World Health Organization Multicountry Survey on Maternal and Newborn Health. BJOG. [Internet]. 2014 Mar [Access Dec 14 2015];121(Suppl. 1):76-88. Available from: http://onlinelibrary.wiley.com/doi/10.1111/14710528.12633/

20. Gupta P, Jahan I, Jograjiya GR. Is vaginal delivery safe after previous lower segment caesarean section in developing country? Niger Med J. [Internet]. 2014 May [Access Dec 14 2015];55(3):260-5. Available from: http:// www.ncbi.nlm.nih.gov/pmc/articles/PMC4089058/. doi: 10.4103/0300-1652.132067

21. World Health Organization (WHO), Human Reproduction Programme (HRP). WHO Statement on Caesarean Section Rates [Internet]. Geneva: WHO; 2015 [Access Dec 14 2015]. Available from: http:// apps.who.int/iris/bitstream/10665/161442/1/WHO_ RHR_15.02_eng.pdf?ua $=1$

22. Ministério da Saúde (BR). Agência Nacional de Saúde Suplementar. Entram em vigor novas regras sobre parto na saúde suplementar [Internet]. Brasília; 2015 [Acesso 14 dez 2015]. Disponível em: http://www.ans. gov.br/aans/noticias-ans/qualidade-da-saude/2923entram-em-vigor-novas-regras-sobre-parto-na-saudesuplementar

23. Silva AAM, Leite AJM, Lamy ZC, Moreira MEL, Gurgel RQ, Cunha AJLA et al. Neonatal near miss in the Birth in Brazil survey. Cad Saúde Pública. [Internet]. 2014 [Access Dec 14 2015];30:S1-S10. Available from: http://www.scielo.br/pdf/csp/v30s1/en_0102-311Xcsp-30-s1-0182.pdf. doi: 10.1590/0102-311X00129613 24. Li F, Wu T, Lei X, Zhang H, Mao M, Zhang J. The apgar score and infant mortality. PLoS One. [Internet]. $2013 \mathrm{Jul}$ [Access Dec 14 2015];8(7):e69072. Available from: http:// journals. plos.org/plosone/article?id=10.1371/journal. pone.0069072 doi: 10.1371/journal.pone.0069072

25. Decat $P$, Nelson E, De Meyer S, Jaruseviciene L, Orozco M, Segura $Z$, et al. Community embedded reproductive health interventions for adolescents in Latin America: development and evaluation of a complex multi-centre intervention. BMC Public Health. [Internet]. 2013 [Access Dec 14 2015];13:31. Available from: http://www.biomedcentral.com/1471-2458/13/31. doi: 10.1186/1471-2458-13-31 
26. Fiedler MW, Araujo A, Souza MCC. A prevenção da gravidez na adolescência na visão de adolescentes. Texto Contexto Enferm. [Internet]. 2015 Jan-Mar [Access Nov 11 2016]; 24(1): 30-7. Available from: http://www.scielo. br/pdf/tce/v24n1/pt_0104-0707-tce-24-01-00030.pdf. DOI 10.1590/0104-07072015000130014. Creative Commons (CC BY).

This license lets others distribute, remix, tweak, and build upon your work, even commercially, as long as they credit you for the original creation. This is the most accommodating of licenses offered. Recommended for maximum dissemination and use of licensed materials. 